\title{
LONG TERM EFFECT OF FIBRE SUPPLEMENT AND REDUCED ENERGY INTAKE ON BODY WEIGHT AND BLOOD LIPIDS IN OVERWEIGHT SUBJECTS
}

\author{
Grethe Støa Birketvedt $^{1}$, Jan Aaseth ${ }^{2}$, Jon R. Florholmen ${ }^{1}$ and Kjeld Ryttig ${ }^{3}$
}

University Hospital of Tromsø, Norway; Laboratory of Gastroenterology ${ }^{1}$; Kongsvinger Hospital, Norway²; Karolinska Hospital, Sweden: Obesity Unit ${ }^{3}$

Summary: A weight-reducing potential has been ascribed to high dietary fibre intake. To investigate the practical reliability of this hypothesis, fifty-three moderately overweight females (BMI $\left.>27.5 \mathrm{~kg} / \mathrm{m}^{2}\right)$ on reduced energy intake $(1200 \mathrm{kcal} /$ day $)$ were treated for 24 weeks with a fibre supplement on a randomly, double-blind, placebo-controlled basis. The fibre was administered as an initial dose of $6 \mathrm{~g}$ and a maintenance dose of $4 \mathrm{~g}$. Body weight and blood pressure were recorded weekly during the first 3 months and thereafter every second week. Blood samples were drawn at start and at end of the study. Initial body weights were $75.6 \pm 1.6 \mathrm{~kg}$ in the fibre group versus $75.5 \pm 1.6 \mathrm{~kg}$ in the placebo group. After treatment, mean weight loss in the fibre group was $8.0 \mathrm{~kg}$ versus $5.8 \mathrm{~kg}$ in the placebo group $(\mathrm{p}<0.05)$. Systolic and diastolic blood pressures were significantly reduced in both groups without differences between the groups. Serum concentrations of cholesterol, triglycerides and uric acid were significantly reduced in the group with reduced energy intake, whereas no additional effect was observed when fibre was supplemented. Serum concentrations of potassium and sodium did not change significantly. The results suggest that a dietary fibre supplement in combination with a hypocaloric diet is of value as an adjunct in the management of overweight.

Key words: Dietary fibre; Obesity; Weight reduction; Blood pressure

\section{Introduction}

Increased dietary intake of fibres has been recommended to obtain stable energy intake and avoid metabolic disorders such as obesity, type 2 diabetes, hyperlipidemia and cardiovascular disease $(1,2,5,7,8,10)$. The effect of a dietary fibre supplement to a hypocaloric diet in the treatment of overweight is still controversial $(6,14)$. When critically reviewed, only a few controlled studies have shown a modest weight loss induced by soluble fibre supplement $(11,12,13)$. In addition, there are numerous studies with only limited value due to lack of comparison groups, inadequate sample sizes and short duration of the observations (4).

Fibre supplement in long term studies involves problems with compliance as well as with the adherence to a low-energy diet regimen throughout the observation period. Moreover, it is unknown whether metabolic adjustments to high fibre intake may take place during long-term addition leading to a reduction in the fibre efficacy. Therefore, the aim of the present study was to investigate the effect of the fibre supplement Dumovital (grain and citrus fibre) (Farmafood, Copenhagen, Denmark) on body weight and blood lipids in healthy overweight subjects in a controlled, randomised design for 24 weeks.

\section{Material and methods}

\section{Subjects}

Sixty healthy, mildly overweight females who volunteered to participate in the study were recruited by announcement in the local newspaper. The inclusion criteria were age 18-67 year and body mass index $(\mathrm{BMI})>27.5 \mathrm{~kg} / \mathrm{m}^{2}$. Patients with serious cardial, renal and hepatic diseases were excluded. Patients with a history of gastrointestinal disease, type 1 diabetes, pregnancy, and patients treated with antacids, diuretics, $\mathrm{H}_{2}$-blockers, bulk laxatives, anorectics, and oral contraceptives were also excluded.

\section{Study design}

All subjects were randomised into two groups according to BMI, the fibre group and the placebo group. Fibre tablets (Farma Food, Copenhagen, Denmark) and placebo tablets (identical in taste and appearance as fibre) were prescribed three times daily, 6 tablets to be taken 15 min before meals with $250 \mathrm{ml}$ of water and 4 tablets to be taken at 3 p.m. for 8 weeks (high dosage). The dosage was then reduced to 5 tablets prescribed three times daily for the rest of the treatment period (maintenance dosage). The tablets contained a mixture of fibres from grain and citrus and consisted of 
$15 \%$ soluble fibre and $85 \%$ insoluble fibre. Patients were told to follow a $1200 \mathrm{kcal}$ diet (Libra Slimming Club diet), perform their regular exercise program, and not change their smoking habits during the study. In addition to the food fibre (estimated about $15 \mathrm{~g} /$ day), each subject consumed $6 \mathrm{~g}$ of fibres during the high dosage period of 8 weeks and $4 \mathrm{~g}$ of fibres during the maintenance dosage period, respectively. In addition, each subject received one multivitamin tablet daily. For vitamins and minerals, the content in this tablet was equal to $100 \%$ Recommended Daily Allowance. In order to keep the subjects motivated, they were informed in group sessions, regarding health consequences of overweight three times during the treatment period.

At start, a physical examination was performed, including blood pressure measurement, height, weight and BMI $\left(\mathrm{kg} / \mathrm{m}^{2}\right)$. These procedures were repeated every week during the first 12 weeks and every fourth week during the rest of the treatment period.

Duration of the study was 24 weeks with clinical visits scheduled at the same time each week. Subjects were weighed each week and side effects were recorded. Compliance with the drug treatment was checked by the returned tablets; $80 \%$ compliance was considered acceptable.

Adherence to the $1200 \mathrm{kcal}$ diet was evaluated regularly during the treatment period using a standardised questionnaire. An adherence of $20 \%$ was considered acceptable.

\section{Laboratory tests}

Blood samples were drawn after an overnight fast at start and after 24 weeks. The blood samples were withdrawn into vacutainer tubes containing EDTA $(1 \mathrm{mg} / \mathrm{ml}$, final concentration), and centrifuged at $1000 \mathrm{~g}$ for $10 \mathrm{~min}$ at $4^{\circ} \mathrm{C}$. Hemoglobin and glucose in blood and serum concentrations of cholesterol, triglycerides, uric acid, sodium and potassium

Tab. 1: Characteristics of healthy overweight subjects treated with fibre supplement.

\begin{tabular}{|l|c|c|c|}
\hline Variable & $\begin{array}{c}\text { Fibre } \\
(\mathrm{n}=28)\end{array}$ & $\begin{array}{c}\text { Placebo } \\
(\mathrm{n}=25)\end{array}$ & p-value \\
\hline Age (years) & $37.0 \pm 1.7$ & $43.2 \pm 2.1$ & n.s. \\
\hline Body weight $(\mathrm{kg})$ & $75.6 \pm 1.6$ & $75.5 \pm 1.6$ & n.s. \\
\hline BMI $\left(\mathrm{kg} / \mathrm{m}^{2}\right)$ & $27.5 \pm 0.7$ & $27.5 \pm 0.6$ & n.s. \\
\hline
\end{tabular}

Tab. 2: Blood pressures $(\mathrm{mm} \mathrm{Hg})($ mean \pm SEM) before and after treatment with fibre supplement in healthy overweight subjects. * indicates significant difference from value before start.

\begin{tabular}{|l|c|c|c|c|}
\hline & \multicolumn{2}{|c|}{ Fibre } & \multicolumn{2}{c|}{ Placebo } \\
& start & end & start & end \\
\hline $\begin{array}{l}\text { Systolic } \\
\text { blood } \\
\text { pressure }\end{array}$ & $127.1 \pm 2.7$ & $120.5 \pm 2.6 *$ & $134.0 \pm 3.1$ & $126.8 \pm 2.1 *$ \\
\hline $\begin{array}{l}\text { Diastolic } \\
\text { blood } \\
\text { pressure }\end{array}$ & $81.1 \pm 2.3$ & $70.5 \pm 1.6 *$ & $82.9 \pm 2.2$ & $74.6 \pm 1.5^{*}$ \\
\hline
\end{tabular}

were measured using the routine methods of the Central Laboratory Department of Sentralsykehuset of Akershus, Norway.

\section{Ethics}

The study was conducted according to Helsinki declarations and with the approval of the Ethical Committee of the Health Region I in Norway. All subjects gave their informed consent.

\section{Statistical analysis}

Statistical analysis was performed in those patients who fulfilled the study according to the protocol. Differences in consecutive weight changes between the fibre and the placebo group were evaluated by using Wilcoxon rank sum test. Significance of differences between the groups was assessed by the paired Student's t tests, defining a p-value $<0.05$ as statistically significant.

\section{Results}

Of the 60 intended-to-treat patients (30 in each group) randomised to fibre and placebo treatment, 53 subjects $(28 / 25)$ in the fibre group and placebo group, respectively entered the study. Seven of the subjects were not included due to sudden events between the randomisation and the start. The remaining 53 subjects completed the study according to the protocol. The treatment was well tolerated. No side effects were reported in neither group.

\section{Characteristics of subjects}

At start of the study there were no significant differences between age, gender, body weight, BMI and duration of overweight (Table 1). There was a significant weight loss in

Fig. 1: The long term effect of fibre supplement $(n=28)$ and placebo $(n=25)$ on body weight in healthy overweight subjects. * indicates significant difference from placebo. For further details, see text.

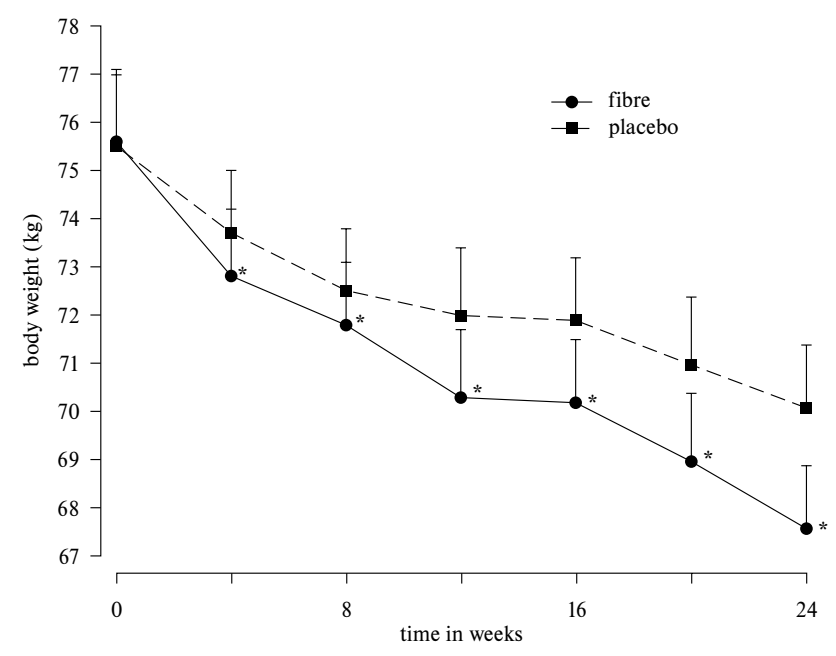


the fibre group from week 4 and onwards as compared to the placebo group $\mathrm{p}<0.05$ ) (Fig 1).

The systolic and diastolic blood pressures were significantly reduced in both groups $(\mathrm{p}<0.01)$ without differences between the groups (Table 2).

\section{Biochemical parameters}

Laboratory values before and after treatment are given in Table 3. Haemoglobin and serum uric acid decreased in both groups during treatment $(p<0.01)$ but no significant differences were observed between the groups $(p>0.5)$. Serum concentrations of cholesterol and triglycerides were significantly reduced in both groups during treatment. No additional effects in blood lipids were observed in the fibre group. Treatment did not change the serum concentrations of potassium and sodium.

Tab. 3: Biochemical parameters (mean \pm SEM) before and after treatment with fibre supplement in healthy overweight subjects. * indicates significant difference from value before start.

\begin{tabular}{|l|c|c|c|c|}
\hline & \multicolumn{2}{|c|}{ Fibre } & \multicolumn{2}{c|}{ Placebo } \\
start & end & start & end \\
\hline $\begin{array}{l}\mathrm{Hb} \\
\left(\mathrm{g} \mathrm{l}^{-1}\right)\end{array}$ & $13.5 \pm 0.1$ & $12.6 \pm 0.2 *$ & $13.9 \pm 0.1$ & $13.1 \pm 0.2 *$ \\
\hline $\begin{array}{l}\text { b-glucose } \\
\left(\mathrm{mmol} \mathrm{l}^{-1}\right)\end{array}$ & $5.3 \pm 0.1$ & $5.1 \pm 0.1 *$ & $5.6 \pm 0.1$ & $5.2 \pm 0.1 *$ \\
\hline $\begin{array}{l}\text { s-cholesterol } \\
\left(\mathrm{mmol} \mathrm{l}^{-1}\right)\end{array}$ & $5.7 \pm 0.2$ & $5.2 \pm 0.2 *$ & $6,0 \pm 0.3$ & $5.5 \pm 0.2 *$ \\
\hline $\begin{array}{l}\text { s-triglycerides } \\
\left(\mathrm{mmol} \mathrm{l}^{-1}\right)\end{array}$ & $1.34 \pm 0.2$ & $0.92 \pm 0.1 *$ & $1.47 \pm 0.2$ & $0.92 \pm 0.1 *$ \\
\hline $\begin{array}{l}\text { s-uric acid } \\
\left(\mathrm{mmol} \mathrm{l}^{-1}\right)\end{array}$ & $270 \pm 11$ & $217 \pm 10 *$ & $259 \pm 14$ & $206 \pm 12 *$ \\
\hline $\begin{array}{l}\text { s-potassium } \\
\left(\mathrm{mmol} \mathrm{l}^{-1}\right)\end{array}$ & $4.3 \pm 0.0$ & $4.3 \pm 0.0$ & $4.3 \pm 0.0$ & $4.2 \pm 0.0$ \\
\hline $\begin{array}{l}\text { s-sodium } \\
\left(\mathrm{mmol} \mathrm{l}^{-1}\right)\end{array}$ & $144 \pm 0.3$ & $143 \pm 0.4$ & $144 \pm 0.5$ & $144 \pm 0.5$ \\
\hline
\end{tabular}

\section{Discussion}

In the present study we have studied the long term effect of fibre supplement in mildly overweight subjects for 24 weeks. Using a treatment regimen with a combination of a hypocaloric diet, and a dietary fibre supplement in addition to regular information meetings, we succeeded in obtaining a high patient compliance and a sustained weight reduction. The weight loss was more pronounced in the fibre group than in the placebo group. This agrees with other fibre studies although of short duration $(1,8)$.

The explanation for the more rapidly achieved weight loss in the fibre group is still not clear, but may be due to the physical properties of the fibre. Fibres with differing physical characteristics can alter gastrointestinal motility and transit times in different ways. Therefore several possible modes of action have been proposed, such as lower energy intake (12), enhanced satiety (13), increased faecal energy excretion (11) or a combination of these reasons. One mechanism could be that fibre compounds bind to cholic acids and thereby reduces the fat absorption (9). However, this effect has been ascribed to the soluble type of fibre (14). The fibre supplement used in this study consisted mostly of insoluble fibre. However, as far as we know there are no reports comparing the weight reducing effect of the two type of fibres. Moreover, in this long term study the weight reducing effect of fibre was not attenuated, suggesting that no rebound mechanisms of actions have occurred.

Concomitant to the weight loss, reductions of serum concentrations of cholesterol and triglycerides were observed. We were, however, not able to confirm previous reports that a dietary fibre supplement can enhance a reduction of these blood lipids beyond that of a hypocaloric diet per se (5). When reviewing the literature, most studies report that soluble fibre improves the lipid profile in blood except for triglycerides $(3,5,16)$, whereas in one report in hamsters insoluble fibre was linked to a reduction of the serum concentration of cholesterol (15). Therefore, the lack of reduction of serum cholesterol observed in this stu$\mathrm{dy}$, is most likely ascribed to a low soluble fibre content in the supplement.

In conclusion, the present investigation shows that this dietary fibre supplement is of value as an adjunct in the management of overweight.

\section{References}

1. Alfieri MA, Pomerleau J, Grace DM, Anderson L. Fiber intake of normal weight, moderately obese and severely obese subjects. Obes Res 1995;3:541-7.

2. Bennett WG, Cerda JJ. Benefits of dietary fiber. Myth or medicine? Postgrad Med 1996; 99:153-6,166-8,171-2.

3. Brown L; Rosner B; Willett WW, Sacks FM. Cholesterol-lowering effects of dietary fiber: a meta-analysis [see comments]. Am J Clin Nutr 1999;69:30-42.

4. Evans E, Miller DS. Bulking agents in the treatment of obesity. Nutr Metabol 1975; 18: 199-203.

5. Glore SR, Van-Treeck D, Knehans AW, Guild M. Soluble fiber and serum lipids: a literature review. J Am Diet Assoc 1994;94:425-36.

6. Kraemer WJ, Volek JS, Clark KL et al. Physiological adaptations to a weight-loss dietary regimen and exercise programs in women. J Appl Physiol 1997;83:270-9.

7. Liu S, Stampfer MJ, Hu FB et al. Whole-grain consumption and risk of coronary heart disease: results from the Nurses' Health Study. Am J Clin Nutr 1999;70: $412-9$

8. Ludwig DS, Pereira MA, Kroenke $\mathrm{CH}$ et al. Dietary fiber, weight gain, and cardiovascular disease risk factors in young adults. JAMA 1999;282:1539-46.

9. Marlett JA, Hosig KB, Vollendorf NW, Shinnick FL, Haack VS, Story JA Mechanism of serum cholesterol reduction by oat bran. Hepatology $1994 ; 20,1450-7$

10. Nelson LH, Tucker LA. Diet composition related to body fat in a multivariate study of 203 men. J Am Diet Assoc 1996;96:771-7.

11. Rigaud D, Ryttig KR, Leeds AR, Bard D, Apfelbaum M. Effects of a moderate dietary fibre supplement on hunger rating, energy input and faecal energy output in young, healthy volunteers: A randomised, double-blind, cross-over trial. Int J Obesity 1987;11(suppl 1):73-8.

12. Røssner S, von Zweigbergk D, Øhlin A, Ryttig K. Weight reduction with dietary fibre supplements: Results of two double-blind randomized studies. Acta Med Scand 1987;222: 83-8.

13. Ryttig KR, Larsen S, Hćgh L. Treatment of slightly to moderately overweight persons: A double-blind placebo-controlled investigation with diet and fibre tablets (DumoVital). Tidsskr Nor Lćgeforen 1984;104:989-91.

14. Saltzman E, Roberts SB. Soluble fiber and energy regulation. Current knowledge and future directions. Adv Exp Med Biol 1997;427:89-97.

15. Wilson TA, Romano C, Liang J, Nicolosi RJ. The hypocholesterolemic and antiatherogenic effects of Cholazol $\mathrm{H}$, a chemically functionalized insoluble fiber with bile acid sequestrant properties in hamsters. Metabolism 1998;47: 959-64. 
16. Wolever TM, Hegele RA, Connelly PW, Ransom TP, Story JA, Furumoto EJ, Jenkins DJ. Long-term effect of soluble-fiber foods on postprandial fat metabolism in dyslipidemic subjects with apo E3 and apo E4 genotypes. Am J Clin Nutr 1997;66: 584-90.

Submitted April 2000.

Accepted June 2000.

Grethe Støa Birketvedt, MD. Ph.D.,

Laboratory of Gastroenterology,

Institute of Clinical Medicine,

University of Tromsø,

Norway.

e-mail: gsb42nor@aol.com 